\title{
Neurocognitive Effects of Electroconvulsive Therapy in Psychiatric Disorders, Mechanism of Action And its Prevention: Review Article
}

\author{
WaheedaShokatKassamKara ${ }^{1 *}$,Khamis Hassan Bakari ${ }^{2}$,Henry Anselmo \\ Mayala ${ }^{2}$,Bing Shao ${ }^{1}$,Mao Jing $^{1}$ \\ ${ }^{I}$ School OfNursing, Tongji Medical College, Huazhong University Of Science And Technology, Hangkong Road \\ No 13 Hankou, Jiefang Avenue, Wuhan, Hubei Province, 430022, P. R. China. \\ ${ }^{2}$ Tongji Medical College, Huazhong University OfScience And Technology, Hubei, Wuhan, China
}

\begin{abstract}
Electroconvulsive therapy has been widely used in the treatment of various psychiatric and somatic conditions such as obsessive compulsive disorder, postpartum psychosis, Parkinson's disease, depression, bipolar disorder and schizophrenia with varying degree of success. Currently, its utilisation has been constrained to limited conditionsdue to its neurocognitive side effects. Neurocognitive impairment associated with ECT treatment includes slow processing speed, verbal and memory deficits which manifest as post ictal confusion, anterograde and/or retrograde memory amnesia, or long-term subjective memory deficit in few patients. Memory deficits caused by ECT usually last for less than six monthsafter the end of ECT treatment, but there is no impairment of acquisition and retention of new memories.Propofol and liothyronine prevent memory deficits post-ECT treatment through different mechanisms.
\end{abstract}

Keywords:Electroconvulsive therapy (ECT), calcium/calmodulin-dependant protein kinase IIa (CaMK Ii $\alpha$ ),Major Depression Disorder (MDD), Glutamic Acid Decarboxylase 65 (GAD 65)

\section{Introduction}

In the early $16^{\text {th }}$ century, treatment of mental illness using convulsion was first experimented using camphor oil, followed by seizure-induction by application of electrical current to the human brain which was introduced by the Italians Cerletti and Bini in $1938^{1}$. Overtime, ECT has been used in the treatment of different psychiatric and some somatic conditions. Currently, ECT has been limited to fewer indications and modified so as to decrease its side effects.ECT has been widely employed in the treatment of other diseases such as obsessive compulsive disorder ${ }^{3}$, postpartum psychosis ${ }^{4}$ and Parkinson's disease with varying degree of success. According to American Psychiatric Association, ECT is widely considered as the most effective antidepressant treatment in medication resistant depression.Multiple studies have also indicated ECT to be effective in the treatment of both manic, depressed phases of bipolar disorder and included it as an optional treatment for refractory bipolar disorder ${ }^{6-11}$.

Some studies have shown that ECT is a useful treatment for a variety of complicated psychiatric conditions especially affective disorders resistant to psychotherapy, medication and other forms of treatment ${ }^{12}$ .Electroconvulsive therapy has also been shown to reduce symptoms related with intractable depression ${ }^{13,14}$. The effectiveness of ECT in the treatment of bipolar depression has also been explained in some studies whereby it has been found to be equally effective in unipolar and bipolar depression and treatment of resistant patient ${ }^{15}$.

Dunne et al. observed that bifrontal ECT is effectual in the treatment of depression to the more usual bitemporal ECT and is linked with fewer memory deficits .Concerning major depression disorder (MDD), ECT has been reported to be helpful in reducing depressive symptoms and is commonly therapeutic indicated to these particular patients . The importance of ECT in the treatment of Treatment Resistant Schizophrenia (TRS) cannot be ignored. Published reports suggest ECT to a be valuable and safe enrichment in TRS including clozapineresistant schizophrenia ${ }^{18,19}$. The American Psychiatric Association on ECT through its task force approved ECT for Treatment-Resistant Schizophrenia ${ }^{20}$. Multiple published reports resolved that adjunctive ECT added to any type of antipsychotics could generate symptomatic improvement in TRS .ECT combined with all types of antipsychotics has also been indicated to be an effective treatment for schizophrenia ${ }^{22}$. Wei at al, in their study, observed that adjunctive ECT is normally safe and well tolerated although 16 patients complained of headache and 32 patients experienced memory impairment .Wenzheng et al. found that combined treatment of ECT and antipsychotic medication in treating refractory schizophrenia leads to improved clinical outcomes, increase the incidence of headaches and memory deficits during treatment and better overall functioning at the end of the treatment ${ }^{24}$. 


\section{Electroconvulsive Therapy And Neurocognitive Deficits}

Major complications of electroconvulsive therapy include confusion, delirium, transient headache, muscle pain, nausea, vomiting, prolonged seizures, teeth damages and circulatory failure. During ECT application and immediately following post-ictal period benign arrhythmias occur frequently. Most adverse effects of memory deficit manifest as post ictal confusion, anterograde and/or retrograde memory amnesia, or long-term subjective memory deficit in a minority of patients ${ }^{25}$.

Numerous studies have also shown that post-ECT neurocognitive impairment includes; slow processing speed, verbal and working memory deficits ${ }^{26}{ }^{27}$ or more widespread cognitive effects ${ }^{28}$ and these might be associated with a shorter duration between the last ECT session and post-treatment assessment in these reports.

However, different studies have attributed the limited utilisation of ECT to its long-lasting cognitive side effects and memory deficits with $12.4 \%$ prevalence for permanent anterograde amnesia in a community setting ${ }^{29,30,31 \text {, and } 32}$. Also, one study not only reported on the restricted use of ECT due to its cognitive adverse effects but also asked if these effects can be fully reversible or remain permanent ${ }^{33}$. The commonest complains from patient post-ECT includes retrograde amnesia and loss of autobiography memory ${ }^{31}$.

Amnesia episode may last from 1 to 6 months after the end of ECT sessions, but there is no impairment of acquisition and retention of new memories ${ }^{34}$.Another author's indicated that memory problems could be solved after a one-month intervention ${ }^{35}$.Fraser et al. observed that memory deficits caused by ECT usually last for less than six months ${ }^{36}$. Apart from most of the patients returning to their previous cognitive status, few still suffers from permanent drawbacks in their memory ${ }^{29}$.

Some studies have demonstrated that various neurocognitive effects related to ECT mostly occurs during the first three days after treatment and they consequently resolve or even improve after sometime ${ }^{37}$.Mohn et al. earlier in their study observed improved neurocognitive function significantly occurs six weeks after ECT treatment ${ }^{54}$. Six months after treatment Mohn and Bjørn further observed that cognitive improvement was maintained and expanded from the previous assessment at six weeks ${ }^{55}$.

Short and long term memory deficits have been indicated to occur shortly and two months post-ECT respectively in patients with major depressive disorder who exhibits poor performance in stating the exact details of stories and most had difficulty in remembering stories of others compared with their personal biography. During follow-up, retrograde amnesia was discovered to be reduced after two months, but impairment in recalling the recent public events in detail persist ${ }^{38}$.

Autobiographical memory (memory for personal events and facts) is vital for self-definition ${ }^{39}$, social interaction ${ }^{40}$ and as a guide for current and future events and analytical reasoning ${ }^{40}$. The deficit in autobiographical memory has been indicated as the most severe cognitive side effect of ECT ${ }^{36,51,52}$.

Moreover, other studies have documented the occurrence of dense retrograde amnesia with gaps in memory of autobiographical events (e.g. Vacation, illness, weddings, etc.) stretching back several years ${ }^{53}$.

Post-ECT euthymic bipolar disorder patients have been shown to have greater memory impairment compared to those with an assumed equal past burden of illness but without prior ECT ${ }^{41}$.Elvira et al. demonstrated that ECT had a significant effect on delayed memory function in patients with major depression with melancholic features. However, four weeks after treatment discontinuation, these functions recovered ${ }^{42}$.Depressive patients who underwent ECT treatment when tested 24-48hrs after the last session were found to show a decline in word fluency, immediate and delay recall of verbal material, reduced ability to discriminate between words previously heard against other words and reduction of reaction time. However, one month later, the neurocognitive deficits of these patients returned or exceeded pretreatment level ${ }^{43}$.

ECT combined with antidepressant during the therapy of treatment resistant depression, leads to increasing incidence of memory deficits compared to ECT alone in the weeks after treatment.Multiple studies reported on the association of ECT cognitive deficits to electrode placement and pulse stimulation. Ute et al. observed in their study that right unilateral ECT treatment was not related with any decrease in general neurocognitive function compared to the psychopharmacologic treatment of bipolar depression ${ }^{45}$. Bilateral electrode (BL) placement is associated with more pronounce short term cognitive deficits than right unilateral (RUL) electrode placement ${ }^{33,46,47,48}$. Svenja et al. revealed that non-psychotic major depression patient who underwent ECT treatment one week after the course of unilateral ECT exhibited anterograde, retrograde and subjective memory deficits more than those patients treated with repetitive transcranial magnetic stimulation (rTMS) or the control group in their study ${ }^{49}$. Use of ultra brief pulse stimulation (ECT) is related with markedly decrease of the acute, short-term and long-term adverse cognitive effects of the ECT treatment ${ }^{50}$.

\section{Mechanism Of Action Of Neurocognitive Deficit In Ect Therapy}


The essential region of the brain concerned with learning and memory is the hippocampus. Normal functions of learning and memory in the brain are maintained by the balance of neuronal transmission between the excitatory neurotransmitter glutamate and the inhibitory substance GABA ${ }^{56}$.

ECT treatment has been proved to induce stress leading to increased hippocampal Glu concentration, which in turn excites the ionotropic receptor GluR, therefore, inhibiting the Akt signaling pathway ${ }^{57}$ decreasing the

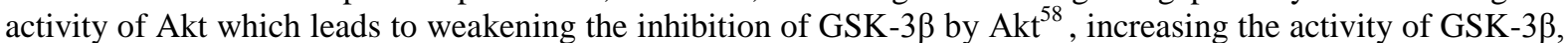
increasing hippocampal protein Tau phosphorylation, decreasing axonal transport efficiency, impairing neural signal transmission thereby causing neuron apoptosis or death, leading to the learning and memory deficit. Phosphorylation of Tau protein leads to reduced axonal transport efficiency thereby impairing neural signal transmission and causing neuron apoptosis or death and eventually leading to impairment of learning and memory. Gang Liu et al proved that ECT-induced stress increases hippocampal Glu concentration and Tau protein phosphorylation leading to learning and memory impairment and is clearly associated with the current and duration of ECT .Previous studies have shown that electroconvulsive seizure for $120-180 \mathrm{sec}$ can lead to cognitive disorders ${ }^{60}$ due to pathological dysfunction of the glutamic acid (Glu) signalling system ${ }^{61,62,63}$. Glu, an excitatory neurotransmitter transmits $\sim 40 \%$ of synapses leading to oxidative stress ${ }^{64}$, causing hippocampal indiscrimination's and saturated long-term potentiation (LTP) ${ }^{62}$, resulting in synaptic plasticity deterioration ${ }^{63}$ and The Akt Pathway or PI3K-Akt Pathway, a signal transduction pathway responsible for the promotion of survival and growth in response to extracellular signals and its main protein includes PI3K (phosphatidylinositol 3-kinase) and Akt (Protein Kinase B).

\section{Prevention Of Neurocognitive Side-Effect Of Electroconvulsive Therapy}

As described above, Tau protein hyperphosphorylation leads to diminishment of neurotransmitter transport and in turn causes accumulation of Glu in damaged neurons, creating cycles, increasing neuron injury and finally causing cognitive impairment. The use of 2, 6-diisopropylphenol decreases the Glu accumulation in the damaged neuron in the brain, thereby preventing cognitive impairment by antagonizing the NMD receptor. Improvement of cognitive function after ECT treatment cessation occurs through the following mechanism by: 1. Directly inducing transient neuroplastic changes in the hippocampus and other cerebral regions involved in learning and memory ${ }^{66}$.

2. Indirectly via its antidepressant properties leading to increased cognitive function

3. Combination of both neuroplastic and antidepressant effect of ECT

The ability of propofol and liothyronine in preventing memory deficits after ECT treatment cannot be neglected. Numerous studies have demonstrated that propofol, an intravenous anaesthetic widely used for general anaesthesia in ECT probably reduces adverse effects of ECT on memory and cognitive function ${ }^{67 a n d}$ ${ }^{68}$.Propofol is an intravenous anaesthetic that is metabolized quickly hence leading to early awakening. It's a short-acting lipophilic drug that quickly crosses the blood-brain barrier with an onset of action ranging from seconds to minutes ${ }^{69}$.

Butterfield et al. also reported greater reduction in post ECT cognitive impairment with propofol compared with thiopental when assessing cognitive states 5 minutes after each ECT by applying various neuropsychological tests, including immediate and delay verbal memory ${ }^{67}$, confirming that propofolanaesthesia is less damaging to cognitive function when compared to older anesthetic agents such as thiopental.

Published report also revealed that propofol administered before ECT inhibited the decrease of glutamic acid in the hippocampus usually observed after ECT ${ }^{63}$.Propofol has also been shown to reverse the change in hippocampal glutamate alpha-aminobutyric acid (GABA) level, and their ratio induced by electroconvulsive shock in depressed rats. It was further demonstrated that propofol reversed the elevated expression of hippocampal glutamic acid decarboxylase 65 (GAD 65) induced by electroconvulsive shock in depressed rats. GABA production pathway in the brain uses glutamate substrate and GAD as a catalyst, whereby GAD 65 is GAD catalyst ${ }^{61}$. Thus explaining the protective effects of propofol.

Another study by Li et al., explained that propofol might also improve ECT-induced learning/memory impairments in depressed rats by enhancing hippocampal activation of calcium/calmodulin-dependant protein kinase II $\alpha$ (CaMK Ii $)$, a critical enzyme in the initiation and early maintenance of synaptic changes that contribute to learning and memory .Liothyronine has been reported to prevent memory deficits after ECT treatment in a patient with Major Depressive Disorder (MDD) ${ }^{71}$. Some studies revealed that patients receiving liothyronine had better scores on the depression and memory scores, six months post-ECT sessions ${ }^{72}$. Also, another study showed that liothyronine could improve verbal learning performance and remote memory in a trial of 30 patients ${ }^{73}$. Findings in a study by Arash et al. concurred with above results by showing that liothyronine improves the performance of verbal and visual memory, attention and delay recall in patients with Major Depressive Disorder undergoing ECT treatment .The mechanism of action of liothyronine is by suppression of 
thyrotropin releasing hormone thereby lowering the required dose of electroshock and consequently decrease the damage and adverse cognitive effects ${ }^{72}$. Moreover, decrease in T3 level in patients receiving liothyronine leads to a temporary disruption in action cytoskeleton responsible for cells from destructive effects of convulsion in amygdala and hippocampus neurons ${ }^{75}$. The above two mechanisms are sensitive to convulsion and play a significant role in memory and learning.

\section{Conclusion}

ECT has been shown to be important in the treatment of different psychiatric and somatic conditions. Neurocognitive deficits which occur after ECT treatment are usually reversible within six month period. Electrode placement positions also determine the extent of cognitive deficits with bilateral electrode placement associated with greater short-term deficits as compared with right unilateral electrode placement. Use of bilateral electrode placement and ultra brief pulse stimulation (ECT) should be investigated further due to their marked short and long term adverse cognitive deficits. Further research on Propofol and liothyronine use in ECT treatment should also be conducted to come up with a guideline which will incorporate either of the two as a standard treatment protocol for ECT treatment.

\section{Disclosure Of Interest}

The authors declare that there was no conflict of interest

\section{References}

[1]. Endler NS. The Origins of Electroconvulsive Therapy (ECT). Convuls Ther.1988; 4(1):5-23.

[2]. Payne NA, Prudic J. Electroconvulsive therapy: Part I. A perspective on the evolution and current practice of ECT. J PsychiatrPract. 2009; 15(5):346-68.

[3]. M.D. Beale, C. H. Kellner, J.T. Pritchett, C. M. Burns, M. A. Jenike, and S. L. Rauch, 'ECT for OCD", Journal of Clinical Psychiatry, vol. 56, no. 2,pp.81-82, 1995.

[4]. J. J. Harding, 'Postpartum psychiatric disorders: a review", Comprehensive Psychiatry, vol. 30, no. 1, pp.109-112, 1989.

[5]. American Psychiatric Association (2001). The Practice of ECT: Recommendation for treatment, Training and Privileging, $2^{\text {nd }}$ edn. American Psychiatric Press: Washington, DC.

[6]. APA. Practice guideline for the treatment of patients with bipolar disorder (revision). Am J Psychiatry 2002; 159:1-50.

[7]. UK ECT Review Group et al. Efficacy and safety of electroconvulsive therapy in depressive disorders: a systematic review and meta-analysis. Lancet 2003; 361:799-808.

[8]. Goodwin GM. Evidence-based guideline for treating bipolar disorder: recommendations from the British Association for Psychopharmacology. J Psychopharmacol 2003; 17:149-73.

[9]. Royal Australian and New Zealand College of Psychiatrist Clinical Practice Guidelines Team for Bipolar Disorder. Australian and New Zealand clinical practice guidelines for the treatment of bipolar disorder. Aust N Z J Psychiatry 2004; 38:280-305.

[10]. Suppes T, Dennehy EB, Hirschfeld RM, et al. The Texas implementation of medication algorithms: update to the algorithms for treatment of bipolar I disorder. J Clin Psychiatry 2005; 66:870-86.

[11]. Yatham LN, Kennedy SH, O’Donovan C, et al. Canadian Network for Mood and Anxiety Treatments (CANMAT) guidelines for the management of patients with bipolar: consensus and controversies. Bipolar Disord 2005;7(Suppl 3):5-69.

[12]. Chamberlin E, Tsai GE. 1998. A glutamatergic model of ECT-induced memory dysfunction. Harv Rev Psychiatry, 5:307-17.

[13]. Neylan TC, Canick JD, Hall SE, et al. 2001. Cortisol levels predict cognitive impairment induced by electroconvulsive therapy. Biol Psychiatry, 50; 331-6.

[14]. TaiebO,Flament MF, Corcos M, et al.2001. Electroconvulsive therapy in adolescents with mood disorder: Patients' and parents' attitudes. Pschiatr Res, 104:183-90.

[15]. MeddaP,Perugi G, Zanello S, et al. Response to ECT in bipolar I, bipolar II and unipolar depression. J Affect Disord.2009; 118 (13):55-59.

[16]. Dunne RA, McLoughlin DM (2012) Systematic review and meta-analysis of bifontral electroconvulsive therapy versus bilateral and unilateral electroconvulsive therapy in depression. World J Biol Psychiatry 13:248-258.

[17]. M. T. Berlim, F. Van den Eynde, and Z. J. Daskalakis, "Efficacy and acceptability of high frequency repetitive transcranial magnetic stimulation (RTMS) versus electroconvulsive therapy (ECT) for major depression: a systematic review and met-analysis of randomized trials", Depression and Anxiety, vol. 30, no. 7, pp.614-623, 2013.

[18]. Petrides G, Malur C, Braga RJ, Bailine SH, Schooler NR, Malhotra AK, et al. Electroconvulsive therapy augmentation in clozapineresistant schizophrenia: a prospective, randomized study. A J Psychiatry. 2015; 172(1):52-8.Epub 2014/08/27. Doi:10.1176/appi.ajp.2014.13060787 PMID: 25157964.

[19]. Lally J, Tully J, Robertson D, Stubbs B, Guaghran F, MacCabe JH. Augmentation of clozapine with electroconvulsive therapy in treatment resistant schizophrenia: A systematic review and meta-analysis.SchizophrRes.2016;171 (1-3):215 24.Epub2016/02/02.

a. $\quad$ doi:1010.1016/j.schres.2016.01.024 PMID: 26827129.

[20]. Weiner RD. The practice of electroconvulsive therapy: Recommendations for treatment, training, and privileging: A Task Force Report of the American Psychiatric Association: American Psychiatric Pub; 2008.

[21]. Wang WZ, Pu CC, Jiang JL, Cao QY, Wang JJ, Zhao M, et al. Efficacy and safety of treating patients with refractory schizophrenia with antipsychotic medication and adjunctive electroconvulsive therapy: a systematic review and meta-analysis [In Chinese]. Shanghai Archives of Psychiatry.2015; 27 (04):206-19.

[22]. Tharyan P, Adams CE. Electroconvulsive therapy for schizophrenia. Cochrane Database Syst Rev. 2005;(2): CD000076. Epub 2005/04/23. doi: 10.1002/146651858.CD000076.pub2PMID:2015;27

[23]. Wei Zheng, Cao X-L, Ungvari GS, Xiang Y-Q, Guo T, Liu Z-R, et al. (2016) Electroconvulsive Therapy Added to Non-Clozapine Antipsychotic Medication for treatment Resistant Schizophrenia: Meta-Analysis of Randomized Controlled Trials. PLoS ONE 11(6): e0156510. doi: 10.1371/journal.pone.0156510. 
[24]. Wenzheng WANG, Chengcheng PU, Jiangling JIANG, Xinyi CAO, Jijun WANG, Min ZHAO, Chunbo LI. Efficacy and safety of treating patients with refractory schizophrenia with antipsychotic medication and adjunctive electroconvulsive therapy: a systematic review and meta-analysis. Shanghai Arch Psychiatry. 2015, 27(4):doi:http://dx.doi.org/10.11919/j.issn.1002-0829.215093.

[25]. Verwijk E, Comijs HC, Kok RM, Spaans HP, Stek ML, Scherder EJ. Neurocognitive effects after brief pulse and ultrabrief pulse unilateral electroconvulsive therapy for major depression: a review. J Affect Disord.2012; 140:233-43.

[26]. Ng C, Schweitzer I, Alexopoulos P, et al. Efficacy and cognitive effects of right unilateral electroconvulsive therapy. J ECT. 2000; $16(4): 370-379$.

[27]. O Connor M, Brenninkmeyer C, Morgan A, et al. Relative effects of repetitive transcranial magnetic stimulation and electroconvulsive therapy on mood and memory: a neurocognitive risk-benefit analysis. CognBehav Neurol.2003; 16 (2):118-127.

[28]. Kellner CH, Knapp R, Husain MM, et al. Bifrontal, bitemporal and right unilateral electrode placement in ECT: randomized trial. Br J Psychiatry. 2010;196(3):226-234

[29]. B. Sadock and V. Sadock, Synopsis of Psychiatry, Lippincott Williams and Wilkins, Philadephia, Pa, USA, 10 ${ }^{\text {th }}$ edition, 2014.

[30]. P. R. Joun, ''E lectroconvulsive therapy" in Comprehensive Textbook of Psychiatry, B. J. Sadock, and P. Ruiz, Eds., pp.32853314, Lippincott Williams \& Wilkins, New York, NY, USA, $9^{\text {th }}$ edition, 2009.

[31]. Rose D, Fleischmann, P Wykes T, et al. Patient's perspective on electroconvulsive therapy: a systematic review. BMJ.2003; 326(7403): 1363 .

[32]. Food and Drug Administration. Meeting to discuss the classification of electroconvulsive therapy devices (ECT). FDA Executive Summary. $\quad$ January 2011. http://www.fda.gov/downloads/AdvisoryCommittees/CommitteesMeetingMaterials/MedicalDevicesAdvisoryCommittee/neurologic alDevicesPanel/UCM240933.pdf.

[33]. Sackiem ha, Prudic J, Fuller R, Keilp J, Lavpri PW, Olfson M. The cognitive effects of electroconvulsive therapy in community settings. Neuropsychopharmacology 2007; 32:244-254.

[34]. Moser CM, Lobato MI, Belmonte-de-Abreu P. Evidence of the effectiveness of electroconvulsive therapy in the psychiatric practice. Rev Psiquiatr Rio GdSul, 2005; 302-10.

[35]. D. W. Falconer, J. Cleland, S. Fielding, and I. C. Reid, 'Using the Cambridge neuropsychological test automated battery (CANTAB) to assess the cognitive impact of electroconvulsive therapy on visual and visuospatial memory," Psychological Medicine, vol. 40, no. 6, pp.1017-1025,2010.

[36]. L. M. Fraser, R. E. O Carroll, and K. P. Ebmeier, 'The effect of electroconvulsive therapy autobiographical memory: a systematic review," The Journal of ECT, vol. 24, no. 1, pp. 10-17, 2008.

[37]. Semkovska M, McLoughlin DM. Objective cognitive performance associated with electroconvulsive therapy for depression: a systematic review and meta-analysis. Biol Psychiatry. 2010; 68(6):568-577.

[38]. S. H. Lisanby, J. H. Maddox, J. Prudic, D. P. Devanand, and H. A. Sackiem, 'The effects of electroconvulsive therapy on memory of autobiographical and public events,” Archives of General Psychiatry, vol. 57, no. 6, pp. 581-590, 2000.

[39]. Welzer H, Markowitsch HJ. Towards a bio-psycho-social model of autobiographical memory. Memory. 2005; 13(1):63-78.

[40]. Bluck S. Autobiographical memory: exploring its functions in everyday life. Memory. 2003; 11(2):113-123.

[41]. MacQueen G, Parkin C, Marriott M, et al. The long-term impact of treatment with electroconvulsive therapy on discrete memory systems in patients with bipolar disorder. J Psychiatry Neurosci. 2007; 32(4):241-249.

[42]. Boere E, Kamperman AM, van'tHoog AE, van den Broek WW, Birkenhäger TK (2016) Anterograde Amnesia during Electroconvulsive Therapy: A Prospective Pilot-Study in Patients with Major Depressive Disorder. PLoS ONE 11(10):e0165392. Doi.1371/journal.pone.0165392.

[43]. Weeks HR III, Tadler SC, Smith KW, Iacob E, Saccoman M, et al. (2013) Antidepressant and Neurocognitive Effects of Isoflurane Anesthesia versus Electroconvulsive Therapy in Refractory Depression. PLoS ONE 8(7):e69809.doi:1371/journal.pone.0069809.

[44]. Guo-Min Song ,XuTian, Ting Shuai, Li-Juan Yi, et al. Treatment of Adults With Treatment-Resistant Depression: Electroconvulsive Therapy Plus Antidepressant or Electroconvulsive Therapy Alone? Evidence From an Indirect Comparison Metaanalysis. Medicine 94(26):e1052:doi:10.1097/MD.0000000000001052.

[45]. Ute Kessler, Helle K. Schoeyen, Ole A. Andreassen, Geir E. Eide, et al. The effect of electroconvulsive Therapy on Neurocognitive Function in Treatment-Resistant Bipolar Disorder Depression. J Clin Psychiatry 2014; 75(11):e1306e1313.doi:10.4088/JCP.13m08960.

[46]. Sackeim HA, Prudic J, Devanand DP, et al. A prospective, randomized, double-blinded comparison of bilateral and right unilateral electroconvulsive therapy at different stimulus intensities. Arch Gen Psychiatry 2000; 57:425-434.[PubMed: 10807482]

[47]. Sackiem HA, Prudic J, Devanand DP, et al. Effects of stimulus intensity and electrode placement on the efficacy and cognitive effects of electroconvulsive therapy. N Engl J Med 1993; 328:839-846. [PubMed: 8441428].

[48]. Sackiem HA, Dillingham, EM.,Prudic, J., Cooper, T., McCall, W. V., Rosenquist, P., Isenberg, K., Mulsant, BH., Haskett, R.F., 2009. Effect of concomitant pharmacotherapy on electroconvulsive therapy outcomes:short-term efficacy and adverse effects. Archives of General Psychiatry 66,729-737.

[49]. Svenja C. Schulze-Rauschenbach, UTA Harms, Thomas E.Schlaepfer, Wolfgang Maier, Peter Falkai and Michael Wagner. Distinctive neurocognitive effects of repetitive transcranial magnetic stimulation and electroconvulsive therapy in major depression. BJP 2005,186:410-416.doi:10.1192/bjp.186.5.410

[50]. Sackeim HA, Prudic J, Mitchell S. Nobler, Linda Fitzsimons, et al. Effects of Pulse and Width and Electrode Placement on the Efficacy and Cognitive Effects of Electroconvulsive Therapy.BrainStimul. 2008 April 1; 1(2):71-83, doi:10.1016/j.br.2008.03.001.

[51]. Sackeim, HA. The cognitive effects of electroconvulsive therapy. In: Moos, WH; Gamzu, ER; Thal, LJ., editors. Cognitive Disorders: Pathophysiology and Treatment. New York: Marcel Dekker; 1992. p. 183-228.

[52]. Sackeim HA. Memory and ECT: From polarization to reconciliation. J ECT. 2000; 16:87-96. [PubMed: 10868319].

[53]. Donahue AB. Electroconvulsive therapy and memory loss: a personal journey. J ECT. 2000; 16:133-143. [PubMed: 108668323].

[54]. Mohn C, Rund BR. Significantly improved neurocognitive function in major depressive disorders at 6 weeks after ECT. J Affect Disord (2016) 202:10-5.di:10.1016/j.jad.2016.03.062.

[55]. Mohn c AND Rund BR (2016) Maintained improvement of Neurocognitive Function in Major Depressive Disorders 6 Months after ECT. Front. Psychiatry 7:200.doi:10.3389/fpsyt.2016.00200.

[56]. Car H, Wisniewski K. Similarities and interactions between GABAERGIC and glutaminergic systems. Rocz. Akad. Med. Bialymst. 1998; 43: 5-26.

[57]. Wang HY, Wang GL, Yu YH and Wang Y: The role of phosphoinositide-3-kinase/Akt pathway in propofol-induced postconditioning against focal cerebral ischemia-reperfusion injury in rats. Brain Res 1297: 177-184, 2009. 
[58]. Freitas AE, Machado DG, Budni J, et al: Antidepressant-like action of the bark ethanolic extract from Tabebuiaavellanedae in the olfactory bulbectomized mice. J Ethnopharmacol 145: 737-745, 2013.

[59]. Gang Liu, Chao Liu, Xue-Ning Zhang. Comparison of the neuropsychological mechanisms of 2,6-diisopropylphenol and Nmethyl-D-aspartate receptor antagonist against electroconvulsive therapy induced learning memory impairment in depressed rats. doi: $10.3892 / \mathrm{mmr} 2015.803$.

[60]. Conrad MS and Richard A: The handbook for electroconvulsive therapy. $1^{\text {st }}$ ed. Eagle Race Medical Technologies Company Press California, 1999.

[61]. Luo J, Mins, Wei K, Li P, Dong J and Liu YF: Propofol protects against impairment of learning-memory and imbalance of hippocampal Glu/GABA-induced by electroconvulsive shock in depressed rats. J anesth 255:657-665, 2011.

[62]. Andrade C, Singh NM, Thyagarajan S, Nagaraja N, Sanjay Kumar Rao N and Suresh Chandra J: Possible glutamatergic and lipid signalling mechanisms in ECT - induced retrograde amnesia: experimental evidence for involvement of COX-2 and review of literature. J Psychiatr Res 42: 837-850, 2008.

[63]. Dong J, Mins, Wei K, Li P, Cao J and Li Y: Effects of electroconvulsive therapy and propofol on spatial memory and glutamatergic system in hippocampus of depressed rats. J ECT 26: 126-130, 2010.

[64]. Kartalcis, Karabulut AB, Ozcan AC, Porgali E and Unal S Acute and chronic effects of electroconvulsive treatment on oxidative parameters in schizophrenia patients. ProgNeuropsychopharmacolBiol Psychiatry 35:16689-11694, 2011.

[65]. Kato N: Neurophysiological mechanisms of electroconvulsive therapy for depression. Neurosci Res 64: 3-11, 2009.

[66]. Nordanskog P, Dahlstrand U, Larsson EM, Knutsson L, Johanson A. Increase in hippocampal volume after electroconvulsive therapy in patients with depression: a volumetric magnetic resonance imaging study. J ECT (2010) 26: 62-7. doi: 10.1097/YCT.0b013e3181a95da8.

[67]. Butterfield NN, Graf P, Macleod BA, Ries CR, Zis AP. Propofol reduces cognitive impairment after electroconvulsive therapy. J. ECT 2004; 20: 3-9.

[68]. GeretseggerC,Nickel M, Judendorfer B, Rochowanski E, Novak E, Aichhorn W. Propofol and methohexital as anesthetic agents for electroconvulsive therapy: A randomized, double-blind comparison of electroconvulsive therapy seizure quality, therapeutic efficacy, and cognitive performance. J. ECT 2007; 23: 239-243.

[69]. Patel SB, Kress JP. Sedation and analgesia in the mechanically ventilated patient. Am. J. Respir. Crit. Care Med. 2012; 185: 486497.

[70]. $\mathrm{Li} \mathrm{X}, \mathrm{Li} \mathrm{W}$, Luo $\mathrm{J}$ et al. Effects of propofol on the activation of hippocampal CaMK Ii in depressed rats receiving electroconvulsive therapy. J. ECT 2012; 28: 242-247.

[71]. A. Hamidia, M. Ghadiri, and A. AfkhamEbrahimi, 'Comparison of memory impairment due to electroconvulsive therapy in depressed patients receiving liothyronine and vitamin B12,'’Iranian Journal of Psychiatry and Clinical Psychology, vol. 12, no. 1, pp. 16-20, 2006.

[72]. A. Masoudzadeh, S. T. Yahyavi, H. Rashidi, R. A. Mohammad pour, and R. Kiani, 'Use of liothyronine in preventing Electroconvulsive therapy-induced memory impairment: evaluation," 'Psychiatrist, vol. 37, no. 2, pp. 49-53, 2013.

[73]. R. A. Stern, S. Legendre, A. Thorner et al., ''Exogenous thyroid hormone diminishes the amnestic side effects of electroconvulsive therapy,' Journal of the International Neuropsychological Society, vol. 6, p. 235, 2000.

[74]. ArashMohagheghi, AsgharArfaie, ShahrokhAmiri, MasoudNouri, Salman Abdi and Salman Safikhanlou. Preventive Effect of Liothyronine on Electroconvulsive Therapy-Induced Memory Deficit in Patients with Major Depressive Disorder: A Double-Blind Controlled Clinical Trial. BioMed Research International, http://dx.doi.org/10.155/2015/503918.

[75]. C. Siergrist and A. Kaiser, 'Thyroxin-dependent modulation of action polymerization in cultured astrocytes: a novel extra under action of thyroid hormone,’ The Journal of Biological Chemistry, vol. 265, no. 9, pp. 5296-5302, 1990. 